\title{
Atorvastatin Given prior to Electrical Cardioversion Does Not Affect the Recurrence of Atrial Fibrillation in Patients with Persistent Atrial Fibrillation Who Are on Antiarrhythmic Therapy
}

\author{
Kenan Demir ${ }^{a} \quad$ Ilknur Can $^{a}$ Fatih Koc $^{\mathrm{b}}$ Mehmet Akif Vatankulu ${ }^{\mathrm{a}}$ Selim Ayhan ${ }^{\mathrm{a}}$ \\ Hakan Akilli $^{\mathrm{a}}$ Alpay Aribas ${ }^{\mathrm{a}}$ Yusuf Alihanoglu ${ }^{\mathrm{a}}$ Bulent Behlul Altunkeser ${ }^{\mathrm{a}}$ \\ a Department of Cardiology, School of Medicine, Selcuk University, and ${ }^{\mathrm{b}}$ Department of Cardiology, School of \\ Medicine, Gaziosmanpasa University, Tokat, Turkey
}

\section{Key Words}

Atorvastatin · Atrial fibrillation · Electrical cardioversion

\begin{abstract}
Objective: In this study, our aim was to evaluate the effect of a higher dose of atorvastatin on the recurrence rate of atrial fibrillation (AF) after electrical cardioversion (EC) in addition to antiarrhythmic therapy. Subjects and Methods: 48 patients with persistent AF were included in this study. The patients were randomized to an atorvastatin 40-mg treatment group and a control group. Atorvastatin was started 3 weeks before EC and was continued for 2 months after EC. EC was performed using biphasic shocks after 3 weeks of treatment with the orally administered anticoagulant warfarin. Lipid and inflammatory parameters (high-sensitivity C-reactive protein, white blood cell count and fibrinogen level) were evaluated at the baseline and before EC. The endpoint of this study was electrocardiographically confirmed recurrence of AF of $>10$ min. Results: There were no significant differences in baseline characteristics and lipid and inflammatory marker levels between the treatment and control groups. Total cholesterol and low-density lipoprotein levels were significantly decreased in patients taking atorvastatin for 2 months compared with baseline values (174 \pm 31 vs. $129 \pm 25 \mathrm{mg} /$
\end{abstract}

$\mathrm{dl}, \mathrm{p}=0.001$, and $112 \pm 23$ vs. $62 \pm 20 \mathrm{mg} / \mathrm{dl}, \mathrm{p}=0.001$, respectively), while no significant change occurred in control patients $(168 \pm 26$ vs. $182 \pm 29 \mathrm{mg} / \mathrm{dl}, \mathrm{p}=0.07$, and $99 \pm 18$ vs. $108 \pm 26 \mathrm{mg} / \mathrm{dl}, \mathrm{p}=0.1$, respectively). At the end of the 2-month follow-up period, 9 patients (20.5\%) experienced AF recurrence, and there was no significant difference in AF recurrence rate between the treatment and control groups (26 vs. $13 \% ; p=0.2$ ). Conclusion: Atorvastatin therapy prior to EC does not prevent the recurrence of arrhythmia in patients with persistent AF who are receiving antiarrhythmic therapy.

Copyright $\odot 2011$ S. Karger AG, Basel

\section{Introduction}

Atrial fibrillation (AF) is the most common arrhythmia and is associated with significant morbidity and mortality, accounting for one third of all strokes over the age of 60 years [1]. It is associated with cardiac surgery and many forms of heart diseases including coronary artery disease (CAD), arterial hypertension and valvular disease [2]. In many patients, paroxysms of AF that terminate spontaneously eventually become persistent, requiring cardioversion for the restoration of sinus rhythm.

\section{KARGER}

Fax +4161306 1234

E-Mail karger@karger.ch

www.karger.com
(C) 2011 S. Karger AG, Basel

1011-7571/11/0205-0464\$38.00/0

Accessible online at:

www.karger.com/mpp
Fatih Koc

Department of Cardiology, School of Medicine

Gaziosmanpasa University

TR-60100 Tokat (Turkey)

Tel. +90 555464 1141, E-Mail drfatkoc@gmail.com 
It is known that AF alters the electrophysiological, structural and contractile properties of the atrium in a way that makes the atrial environment more prone to future AF episodes [3]. Other factors involved in the induction or maintenance of AF include focal inflammation, endothelial/endocardial dysfunction, oxidative stress, ischemia and autonomic nervous system activity $[2,4]$. Evidence for an inflammatory contribution has initially been suggested by the high incidence of AF (25-40\%) after cardiac surgery and the association of AF with pericarditis and myocarditis [5]. The presence of systemic inflammation, which is determined by elevated levels of high-sensitivity C-reactive protein (hs-CRP), is associated with the presence of AF and is an independent predictor of AF [6, 7]. Patients with persistent AF have higher levels of hs-CRP than patients with paroxysmal AF [8].

Statins, which are known to have anti-inflammatory and pleiotropic effects, have been shown to have beneficial effects on AF in a variety of reports [9-11]. In a retrospective study, it was found that patients with persistent lone AF who took statins had decreased AF recurrence after successful electrical cardioversion (EC) [9]. In patients with $\mathrm{CAD}$, statins reduced the incidence of $\mathrm{AF}$ in a manner that was independent of the statin lipid-lowering effect [10]. Ozaydin et al. [11] showed that patients receiving atorvastatin $(10 \mathrm{mg})$ prior to EC maintained sinus rhythm longer when compared with the patients receiving no drug. However, in another prospective study, pravastatin did not reduce the recurrence of AF after EC [12]. The aim of the present study was to evaluate the effect of a higher dose of atorvastatin on the recurrence rate of AF and on inflammatory markers after successful EC in patients with persistent AF. We used well-known and easily determined inflammatory markers such as hs-CRP, white blood cell count and fibrinogen [13].

\section{Subjects and Methods}

\section{Study Population and Protocol}

Patients $(\mathrm{n}=48)$ who had persistent AF ( $>1$ week) and who were scheduled for EC were included in our prospective, open-label, single-center study. The exclusion criteria were: paroxysmal AF episodes; unsuccessful cardioversion history; thyroid dysfunction; significant heart valve disease; liver disease or elevated liver enzymes; recent acute coronary event in the last 6 months; revascularization history in the last 1 year; autoimmune or inflammatory diseases; pregnancy or lactation; significant renal functional impairment; New York Heart Association class III or IV heart failure; a left atrium size of $>5.5 \mathrm{~cm}$, and a history of statin therapy. Patients were chosen randomly and grouped in the order of admission into an atorvastatin $40 \mathrm{mg}(\mathrm{n}=24)$ and a control group $(\mathrm{n}=$
24). All patients received warfarin treatment at an international normalized ratio of 2.0-3.0 for a minimum of 3 weeks before and 4 weeks after EC. Atorvastatin was started 3 weeks before EC and was continued during the 2-month follow-up period.

Amiodarone was administered as a 150 -mg bolus, intravenously over $10 \mathrm{~min}$, followed by a continuous infusion at $0.5-$ $1 \mathrm{mg} / \mathrm{min}$ for $24 \mathrm{~h}$ as per the ACC/AHA/ESC (American College of Cardiology/American Heart Association/European Society of Cardiology) 2006 Guidelines [2]. External cardioversion was performed at the time of amiodarone therapy in the fasting state under general anesthesia with intravenous propofol $(2 \mathrm{mg} / \mathrm{kg})$. $\mathrm{R}$ wave synchronized biphasic shocks were delivered to all the patients by a step-up protocol of 100, 200 and $360 \mathrm{~J}$ at an anterolateral electrode position. When unsuccessful, 2 anteroposterior shocks of 200 and 360 J were applied. Despite the EC procedure, AF in 2 patients could not be converted to sinus rhythm, and the patients were excluded from the study. External cardioversion was considered successful when sinus rhythm lasted $\geq 1 \mathrm{~min}$ after the shock. After successful cardioversion, all patients were given oral amiodarone or propafenone for maintenance of sinus rhythm. The patients were discharged on the following day and were instructed to attend the outpatient clinic normally once a week for 2 months, but they were also instructed to attend the outpatient clinic whenever they experienced symptoms suggestive of AF. Early AF recurrence was defined as relapse into $\mathrm{AF}$ within a week.

Three weeks before EC, all the study subjects underwent transthoracic echocardiography and electrocardiography. Patients whose international normalized ratio level was found to be below 2 on the scheduled day of EC underwent transesophageal echocardiography to exclude intracardiac thrombi. Venous blood for complete blood count, hs-CRP, fibrinogen, total cholesterol and high-density lipoprotein cholesterol analysis were obtained 3 weeks before EC and on the day of EC before the procedure was started. hs-CRP levels were determined by the Dade Behring BN II N High Sensitivity CRP assay. White blood cell count was determined using a Coulter counter. The fibrinogen level was determined by standard analytical methods. The follow-up lasted 2 months and the endpoint of the study was electrocardiographically confirmed recurrence of AF for $>10 \mathrm{~min}$. No patients were lost to follow-up. When recurrence was documented, atorvastatin and antiarrhythmic medication used to maintain sinus rhythm were stopped. The participants consented to the study and the hospital's ethics committee approved the protocol.

\section{Statistical Analysis}

Parametric disturbed continuous variables are expressed as means $\pm \mathrm{SD}$, and nonparametric disturbed variables as medians (interquartile ranges, IQR). The Mann-Whitney $\mathrm{U}$ test was used for comparison of nonparametric variables, and the Student $t$ test for comparison of parametric variables. Categorical variables were compared by the $\chi^{2}$ test. The baseline and pre-EC levels of hs-CRP and white blood cell count were compared by the Wilcoxon test. Baseline and pre-EC levels of total cholesterol, lowdensity lipoprotein (LDL) cholesterol and fibrinogen were compared by paired $t$ tests for each groups. An ANCOVA model that included statin treatment as a fixed main effect, with the baseline left atrial dimension, BMI, age, gender and diabetes mellitus as covariates. $p<0.05$ was considered significant. The Statistical Package for the Social Sciences, version 11.0 (SPSS Inc., Chicago, Ill., USA) was used for statistical analysis. 
Table 1. Baseline characteristics and medications

\begin{tabular}{lccc}
\hline & Atorvastatin $(\mathrm{n}=22)$ & Control (n=22) & $\mathrm{p}$ \\
\hline Age, years & $62 \pm 9$ & $60 \pm 10$ & 0.7 \\
Female sex & $12(52 \%)$ & $13(56 \%)$ & 0.7 \\
AF duration, months & $8 \pm 4.3(1.5-12)^{1}$ & $7.5 \pm 4.7(1-12)^{1}$ & 0.6 \\
BMI & $30 \pm 4.4$ & $31 \pm 3.8$ & 0.5 \\
Smoking & $4(17 \%)$ & $4(17 \%)$ & 1.0 \\
Hypertension & $17(74 \%)$ & $12(52 \%)$ & 0.2 \\
Diabetes mellitus & $2(8 \%)$ & $1(4 \%)$ & 0.5 \\
CAD & $5(21 \%)$ & $3(13 \%)$ & 0.4 \\
Previous cardioversions & $1(4 \%)$ & 0 & 1.0 \\
Left atrial diameter, mm & $42 \pm 4$ & $43 \pm 4$ & 0.4 \\
Left ventricular end-diastolic diameter, mm & $49 \pm 6$ & $51 \pm 4$ & 0.2 \\
Left ventricular ejection fraction, $\%$ & $54 \pm 11$ & $52 \pm 8$ & 0.5 \\
Medication used during study period & & & 0.5 \\
$\quad$ Amiodarone & $21(91 \%)$ & $20(87 \%)$ & 0.5 \\
Propafenone & $1(4 \%)$ & $2(8 \%)$ & 0.6 \\
Calcium channel blockers & $5(22 \%)$ & $6(26 \%)$ & 0.7 \\
Angiotensin-converting enzyme inhibitors & $14(61 \%)$ & $12(52 \%)$ & 0.5 \\
Angiotensin II receptor blockers & $3(13 \%)$ & $2(8 \%)$ & 0.6 \\
\hline
\end{tabular}

Values denote means \pm SD unless specified otherwise.

${ }^{1}$ Figures in parentheses are minimum to maximum ranges.

\section{Results}

EC was unsuccessful in 2 patients, the rhythm of 2 patients spontaneously converted into sinus rhythm before EC, also 1 from each group. There were no significant differences in baseline characteristics and medications between the groups (table 1). The duration of AF ranged from 1 to 12 months. Amiodarone was the antiarrhythmic drug used for the maintenance of sinus rhythm in the majority of the study population. There was no significant difference between the baseline lipid values of the groups (table 2). Before EC, total cholesterol and LDL levels were significantly lower in the atorvastatin group when compared with both baseline and control groups (table 2). There were no significant differences in the mean number of shocks and total energy delivered for EC between the groups. Early relapse into AF within 1 week occurred in 2 patients of the atorvastatin group and in 1 patient of the control group ( $\mathrm{p}>0.5)$ (table 3 ). hs-CRP, white blood cell count and fibrinogen levels were similar at baseline between the atorvastatin and control groups, and they did not change significantly before EC (table 4).

At the end of follow-up, lipid values were evaluated in patients which maintained sinus rhythm in both the group receiving atorvastatin $(\mathrm{n}=16)$ and the control group $(n=19)$. Because of recurrent AF in 9 patients up
Table 2. Lipid parameters

\begin{tabular}{|c|c|c|}
\hline & $\begin{array}{l}\text { Total cholesterol } \\
\text { at baseline }\end{array}$ & $\begin{array}{l}\text { Total cholesterol } \\
\text { before EC }\end{array}$ \\
\hline \multirow{3}{*}{$\begin{array}{l}\text { Atorvastatin }(\mathrm{n}=22), \mathrm{mmol} / \mathrm{l} \\
\text { Control }(\mathrm{n}=22), \mathrm{mmol} / \mathrm{l}\end{array}$} & $4.50 \pm 0.80$ & $3.49 \pm 0.85^{1,2}$ \\
\hline & $4.16 \pm 1.03$ & $4.40 \pm 0.91$ \\
\hline & LDL at baseline & LDL before EC \\
\hline \multirow{3}{*}{$\begin{array}{l}\text { Atorvastatin }(\mathrm{n}=22), \mathrm{mmol} / \mathrm{l} \\
\text { Control }(\mathrm{n}=22), \mathrm{mmol} / \mathrm{l}\end{array}$} & $2.92 \pm 0.62$ & $1.76 \pm 0.62^{1,2}$ \\
\hline & $2.66 \pm 0.54$ & $2.64 \pm 0.75$ \\
\hline & HDL at baseline & HDL before EC \\
\hline Atorvastatin $(\mathrm{n}=22), \mathrm{mmol} / \mathrm{l}$ & $1.11 \pm 0.21$ & $1.14 \pm 0.26$ \\
\hline Control $(\mathrm{n}=22), \mathrm{mmol} / \mathrm{l}$ & $1.09 \pm 0.34$ & $1.06 \pm 0.26$ \\
\hline
\end{tabular}

$\mathrm{HDL}=$ High-density lipoprotein.

${ }^{1} \mathrm{p}<0.01$ compared with baseline in atorvastatin group.

$2 \mathrm{p}<0.01$ compared with control before EC.

to the endpoint of the study, the lipid profile of these patients was not evaluated. Total cholesterol and LDL levels were significantly decreased in patients taking atorvastatin at 2 months compared with baseline values (174 \pm 31 vs. $129 \pm 25 \mathrm{mg} / \mathrm{dl}, \mathrm{p}=0.001$, and $112 \pm 23$ vs. $62 \pm$ 
Table 3. Results of cardioversion

\begin{tabular}{lccc}
\hline & $\begin{array}{l}\text { Atorvastatin } \\
(\mathrm{n}=22)\end{array}$ & $\begin{array}{l}\text { Control } \\
(\mathrm{n}=22)\end{array}$ & $\mathrm{p}$ \\
\hline Number of shocks $^{1}$ & $2(1)$ & $2(1)$ & 0.7 \\
Energy $^{1}, \mathrm{~J}$ & $200(100)$ & $200(100)$ & 0.7 \\
Early relapse & $2(8 \%)$ & $1(4 \%)$ & 1.0 \\
Recurrence of AF at 2 months & $6(26 \%)$ & $3(13 \%)$ & 0.2 \\
\hline
\end{tabular}

${ }^{1}$ Medians with IQR in parentheses.

Table 4. Inflammatory markers

\begin{tabular}{|c|c|c|}
\hline & $\begin{array}{l}\text { Atorvastatin } \\
(\mathrm{n}=22)\end{array}$ & $\begin{array}{l}\text { Control } \\
(n=22)\end{array}$ \\
\hline hs-CRP at baseline, $\mathrm{mg} / \mathrm{dl}$ & $3.1(6.0)$ & $4.4(5.2)$ \\
\hline hs-CRP before EC, mg/dl & $2.2(6.3)$ & $4.5(7.5)$ \\
\hline $\mathrm{p}$ & 1.0 & 0.8 \\
\hline White blood cells at baseline/ $\mu \mathrm{l}$ & $7,950(2,225)$ & $7,050(2,200)$ \\
\hline White blood cells before $\mathrm{EC} / \mu \mathrm{l}$ & $6,950(1,650)$ & $7,350(2,575)$ \\
\hline $\mathrm{p}$ & 0.2 & 0.5 \\
\hline Fibrinogen at baseline ${ }^{1}, \mathrm{mg} / \mathrm{dl}$ & $385 \pm 69$ & $369 \pm 83$ \\
\hline Fibrinogen before $\mathrm{EC}^{1}, \mathrm{mg} / \mathrm{dl}$ & $376 \pm 76$ & $360 \pm 93$ \\
\hline $\mathrm{p}$ & 0.5 & 0.5 \\
\hline
\end{tabular}

Values denote medians with IQR in parentheses unless specified otherwise. ${ }^{1}$ Means $\pm \mathrm{SD}$.

$20 \mathrm{mg} / \mathrm{dl}, \mathrm{p}=0.001$, respectively); no significant change occurred in control patients $(168 \pm 26 \mathrm{vs} .182 \pm 29 \mathrm{mg} /$ $\mathrm{dl}, \mathrm{p}=0.07$, and $99 \pm 18$ vs. $108 \pm 26 \mathrm{mg} / \mathrm{dl}, \mathrm{p}=0.1$, respectively). At the end of the 2-month follow-up, 9 patients (20\%) experienced AF recurrence, and there was no difference in recurrence rates between the groups ( $\mathrm{p}=$ 0.26) (table 3). In the ANCOVA model, the effect of precardioversion statin therapy on AF recurrence was not independent of the following variables: age, BMI, gender, diabetes mellitus, hypertension and left atrial dimension $(\mathrm{F}=1.88 ; \mathrm{p}=0.17)$.

\section{Discussion}

The main finding of this study was the following: atorvastatin did not affect numbers of patients with AF conversion to sinus rhythm before $\mathrm{EC}$ or recurrence rates of $\mathrm{AF}$ after EC when used in addition to antiarrhythmic treatment. We also did not find any difference in the levels of inflammatory markers after 3 weeks of atorvastatin treatment compared with baseline between the groups. These findings are comparable to some studies [12, 14], but not to others $[9,11,15,16]$. It remains unclear how patients benefit from statin therapy for maintaining sinus rhythm after EC. Subgroups should be defined in future studies, such as ischemic heart disease, left ventricular functions, age, diabetes, hypertension, valvular heart disease, chronic obstructive pulmonary disease and high inflammatory burden.

However, statins have been shown to be the most effective and best-tolerated drugs for treating elevated levels of LDL cholesterol [17-19]. Besides lowering lipids, a multitude of potentially cardioprotective effects have been ascribed to these drugs, such as improvement in endothelial function, reduction in oxidative stress, as well as anti-inflammatory and antithrombotic properties [1719]. In addition, statins may exert direct antiarrhythmic effects by modulating the physiochemical properties of the sarcolemma, which results in alterations to transmembrane cardiac ion fluxes that may directly affect the electrophysiological properties of the cardiac muscle [20]. In the Antiarrhythmics versus Implantable Defibrillators study, lipid-lowering therapy decreased the recurrence rate of ventricular arrhythmias in patients treated with implantable cardioverter-defibrillators [21]. In a canine model of sterile pericarditis, elevated levels of CRP were associated with sustained AF, suggesting that electrophysiological changes resulting from inflammation may perpetuate the arrhythmia [21]. Atorvastatin-treated animals had lower CRP levels and shorter AF duration than the control group [22], thereby suggesting that atorvastatin can prevent atrial electrical and structural remodeling and the maintenance of AF by inhibiting inflammation.

Clinical studies also support the efficacy of statins both in primary and secondary prevention of $\operatorname{AF}[15,16$, 23, 24]. Merckx et al. [23] showed that among patients with CAD, statin users had a lower rate of new-onset AF compared with nonusers during a 6.5-year follow-up (7.3 vs. 11.6\%). Dernellis and Panaretou [24] reported that atorvastatin completely resolved AF in $65 \%$ of patients with paroxysmal AF recorded by ambulatory electrocardiography compared with $10 \%$ in a placebo group $(\mathrm{p}=$ 0.02 ). A retrospective study showed that statins helped prevent AF recurrence after EC in lone AF patients [9]. Statins also decreased AF incidence after coronary artery bypass graft or noncardiac thoracic surgery $[15,16]$. Ozaydin et al. [11] showed that at the 3-month follow-up after 
administration of $10 \mathrm{mg}$ atorvastatin, $48 \mathrm{~h}$ before EC, atorvastatin significantly reduced the recurrence rate of AF after EC (12.5 vs. $45.8 \%$; $=0.02)$. The Atorvastatin for Reduction of Myocardial Dysrhythmia after Cardiac Surgery study [25] showed that treatment with atorvastatin, starting 7 days before cardiac surgery and continued in the postoperative period, significantly decreased postoperative AF ( 35 vs. $57 \%$ ) and shortened the postoperative hospital stay.

However, other studies $[12,14]$ have yielded conflicting results. In a prospective study by Tveit et al. [12], pravastatin treatment initiated 3 weeks before EC and continued 6 weeks after EC did not reduce the recurrence rate of AF after EC (35 vs. 33\%). They did not find any difference in the levels of inflammatory and extracellular remodeling markers before or after EC as in our study where we neither found a significant difference in hs-CRP levels nor in recurrence after statin treatment.

Of the antiarrhythmic drugs presently available, oral amiodarone is more efficacious than other drugs for the maintenance of sinus rhythm after EC $[26,27]$. The AF recurrence rate is approximately $30-40 \%$ with amioda- rone. Antiarrhythmics were discontinued in the study by Ozaydin et al. [11] and the dosage left to the discretion of the physician in the study by Tveit et al. [12].

The major limitations of our study were the small sample size and that it was not a placebo-controlled, doubleblind study. Equally, the duration of statin treatment might have been too short to have an effect on atrial remodeling and inflammation. Additionally, the duration of the follow-up was short. Because of these limitations, it is possible that transient or paroxysmal asymptomatic recurrence of AF might have gone undetected. Equally, amiodarone, by controlling heart rate, could have masked the symptoms of paroxysmal AF.

\section{Conclusion}

Our findings suggest that atorvastatin together with EC did not have a beneficial effect in addition to antiarrhythmic treatment. We recommend double-blinded, placebo-controlled studies to clarify the effect of statins on the recurrence rate of AF after EC.

\section{References}

1 Wolf PA, Abbott RD, Kannel WB: Atrial fibrillation: a major contributor to stroke in the elderly - the Framingham Study. Arch Intern Med 1987;147:1561-1564.

2 Fuster V, Rydén LE, Cannom DS, Crijns HJ Curtis AB, Ellenbogen KA, Halperin JL, le Heuzey JY, Kay GN, Lowe JE, et al: ACC/ AHA/ESC 2006 Guidelines for the Management of Patients with Atrial Fibrillation: a report of the American College of Cardiology/American Heart Association Task Force on Practice Guidelines and the European Society of Cardiology Committee for Practice Guidelines (Writing Committee to Revise the 2001 Guidelines for the Management of Patients with Atrial Fibrillation) developed in collaboration with the European Heart Rhythm Association and the Heart Rhythm Society. Circulation 2006;114:254-257.

$\checkmark 3$ Nattel S: New ideas about atrial fibrillation: 50 years on. Nature 2002;415:219-226.

-4 Tamargo J, Caballero R, Delpon E: Pharmacological approach in the treatment of atrial fibrillation. Curr Med Chem 2004;11:13-28.

5 Boos CJ, Anderson RA, Lip GYH: Is atrial fibrillation an inflammatory disorder? Eur Heart J 2006;27:136-149.
-6 Aviles RJ, Martin DO, Apperson-Hansen C, Houghtaling PL, Rautaharju P, Kronmal RA, Tracy RP, van Wagoner DR, Psaty BM, Lauer MS, et al: Inflammation as a risk factor for atrial fibrillation. Circulation 2003;108: 3006-3010

$\checkmark 7$ Anderson JL, Allen Maycock CA, Lappé DL, Crandall BG, Horne BD, Bair TL, Morris SR, Li Q, Muhlestein JB, Intermountain Heart Collaborative Study Group: Frequency of elevation of C-reactive protein in atrial fibrillation. Am J Cardiol 2004;94:12551259.

$>8$ Chung MK, Martin DO, Sprecher D, Wazni O, Kanderian A, Carnes CA, Bauer JA, Tchou PJ, Niebauer MJ, Natale A, et al: C-reactive protein elevation in patients with atrial arrhythmias: inflammatory mechanisms and persistence of atrial fibrillation. Circulation 2001;104:2886-2891.

$\checkmark 9$ Siu CW, Lau CP, Tse HF: Prevention of atrial fibrillation recurrence by statin therapy in patients with lone atrial fibrillation after successful cardioversion. Am J Cardiol 2003;92: 1343-1345.

10 Young-Xu Y, Jabbour S, Goldberg R, Blatt CM, Graboys T, Bilchik B, Ravid S: Usefulness of statin drugs in protecting against atrial fibrillation in patients with coronary artery disease. Am J Cardiol 2003;92:13791383
11 Ozaydin M, Varol E, Aslan SM, Kucuktepe Z, Dogan A, Ozturk M, Altinbas A: Effect of atorvastatin on the recurrence rates of atrial fibrillation after electrical cardioversion. Am J Cardiol 2006;97:1490-1493.

12 Tveit A, Grundtvig M, Gundersen T, Vanberg P, Semb AG, Holt E, Gullestad L: Analysis of pravastatin to prevent recurrence of atrial fibrillation after electrical cardioversion. Am J Cardiol 2004;93:780-782.

13 Gabay C, Kushner I: Acute-phase proteins and other systemic responses to inflammation. N Engl J Med 1999;340:448-454.

14 Garcia-Fernandez A, Marin F, Mainar L, Roldán V, Martínez JG: Effect of statins on preventing recurrence of atrial fibrillation after electrical cardioversion. Am J Cardiol 2006;98:1299-1300.

-15 Amar D, Zhang H, Heerdt PM, Park B, Fleisher M, Thaler HT: Statin use is associated with a reduction in atrial fibrillation after noncardiac thoracic surgery independent of C-reactive protein. Chest 2005;128:34213427.

16 Auer J, Weber T, Berent R, Lamm G, Ng CK, Hartl P, Strasser U, Eber B: Use of HMG-coenzyme A-reductase inhibitors (statins) and risk reduction of atrial fibrillation after cardiac surgery: result of the SPPAF study - a randomised placebo-controlled trial (abstract). Eur Heart J 2004;25(suppl):353. 
17 Holm T, Andreassen AK, Ueland T, Kjekshus J, Frøland SS, Kjekshus E, Simonsen S, Aukrust P, Gullestad L: Effect of pravastatin on plasma markers of inflammation and peripheral endothelial function in male heart transplant recipients. Am J Cardiol 2001;87: 815-818.

18 Laufs U, Endres M, Custodis F, Gertz K, Nickenig G, Liao JK, Böhm M: Suppression of endothelial nitric oxide production after withdrawal of statin treatment is mediated by negative feedback regulation of rho GTPase gene transcription. Circulation 2000;102:3104-3110.

19 Lefer DJ: Statins as potent antiinflammatory drugs. Circulation 2002;106:2041-2042.

-20 Tamargo J, Caballero R, Gomez R, Núñez L, Vaquero M, Delpón E: Lipid-lowering therapy with statins, a new approach to antiarrhythmic therapy. Pharmacol Ther 2007;114: 107-126.
21 Mitchell LB, Powell JL, Gillis AM, Kehl V, Hallstrom AP, AVID Investigators: Are lipid-lowering drugs also antiarrhythmic drugs? An analysis of the Antiarrhythmics versus Implantable Defibrillators (AVID) trial. J Am Coll Cardiol 2003;42:81-87.

22 Kumagai K, Nakashima H, Saku K: The HMG-CoA reductase inhibitor atorvastatin prevents atrial fibrillation by inhibiting inflammation in a canine sterile pericarditis model. Cardiovasc Res 2004;62:105-111.

23 Merckx L, Tieleman RG, Folkeringa RJ, Yigal MP, Fred HN, Emiel CC, Harry JC: Use of statins is associated with reduced incidence of atrial fibrillation in patients with left ventricular hypertrophy and left atrial dilatation (abstract). Heart Rhythm 2004;1(suppl 1):S105.

24 Dernellis J, Panaretou M: Effect of C-reactive protein reduction on paroxysmal atrial fibrillation. Am Heart J 2005;150:1064.
25 Patti G, Chello M, Candura D, Pasceri V, D’Ambrosio A, Covino E, di Sciascio G: Randomized trial of atorvastatin for reduction of postoperative atrial fibrillation in patients undergoing cardiac surgery: results of the ARMYDA-3 (Atorvastatin for Reduction of MYocardial Dysrhythmia After cardiac surgery) study. Circulation 2006;114:14551461.

26 Roy D, Talajic M, Dorian P, Connolly S, Eisenberg MJ, Green M, Kus T, Lambert J, Dubuc M, Gagné P, et al: Amiodarone to prevent recurrence of atrial fibrillation. $\mathrm{N}$ Engl J Med 2000;342:913-920.

27 Kochiadakis GE, Igoumenidis NE, Marketou ME, Kaleboubas MD, Simantirakis EN, Vardas PE: Low dose amiodarone and sotalol in the treatment of recurrent, symptomatic atrial fibrillation: a comparative, placebocontrolled study. Heart 2000;84:251-257. 